\title{
POSSIBILIDADES DE ATUAÇÃO DAS OUVIDORIAS PÚBLICAS DE SAÚDE: UM ESTUDO DE CASO DAS DEMANDAS DO MINISTÉRIO PÚBLICO EM MUNICÍPIO DE PEQUENO PORTE
}

\author{
Possibilities of practice of public health ombudsman: $a$ \\ case study of Public Attorney demands in a small town
}

Rita de Cássia Costa da Silva*

\begin{abstract}
RESUMO
O presente artigo se propôs a estudar as demandas do Ministério Público em um município de pequeno porte, a partir do olhar da ouvidoria da saúde. Foi realizada pesquisa de natureza exploratória e qualitativa que utilizou como método o estudo de caso. As unidades de análise foram as demandas apresentadas pelo Ministério Público à secretaria municipal de saúde no período de janeiro a dezembro de 2010. A pesquisa documental consistiu na análise de 77 ofícios. As variáreis estudadas foram: assunto, natureza e teor das demandas. Os dados foram agrupados conforme as categorias analisadas e apresentaram seis tipos de assunto: comunicação, intimação, recomendação, requisição de atendimento, requisição de informação e solicitação de providências. Quanto à natureza das demandas encontramos: execução de pena, curadoria do idoso, cível, procedimento ordinário, contravenção penal, cível (curatela/interdição), medida de proteção e pedido de providência. A análise do teor das demandas demonstrou que a intervenção do Ministério Público tem características bastante peculiares no município estudado, pois, das 77 demandas, apenas três referemse a serviços indisponíveis no sistema público de saúde. Portanto, apesar de ser objeto de demandas oriundas do Ministério Público, 96,11\% das solicitações foram de serviços ou insumos disponíveis no município. O estudo concluiu

( $\left.^{\star}\right)$ Mestre em Economia da Saúde, Universidade Federal de São Paulo (Unifesp); Especialista em Direito Sanitário, Escola de Saúde Pública de Minas Gerais (ESP/MG); Especialista em Gestão de Sistemas e Serviços de Saúde, Universidade Federal de Minas Gerais (UFMG). Ouvidora do Sistema Único de Saúde na Secretaria Municipal de Saúde de Brumadinho (MG). Psicóloga. Brumadinho/MG - Brasil. E-mail: magripe@gmail.com.
\end{abstract}

Artigo recebido em: 20/10/2012. Revisado em: 21/01/2013. Aprovado em: 22/01/2013 
que, das demandas apresentadas no ano de 2010, nenhuma foi registrada na ouvidoria de saúde. Esse fato demonstra que não há dupla porta para o cidadão acessar seus direitos. No entanto, a não atuação da ouvidoria nesses casos, antecedendo o acesso ao Ministério Público, pode indicar um desconhecimento de sua existência ou função.

Palavras-chave: Direito à Saúde; Ministério Público; Ouvidoria Pública; Sistema Único de Saúde.

\begin{abstract}
This paper aims at studying the demands of the Prosecutor in a small city, from the look of the health ombudsman. We performed an exploratory research and qualitative method used as the case study. The units of analysis were the demands presented by the prosecutor to the municipal health secretariat from January to December 2010. The documentary research was the analysis of 77 offices. The variables studied were subject, nature, content demands. Data were grouped according to categories analyzed and presented six types of matter: communication, subpoena, recommendation, request service, request information and request action. The nature of the demands met: execution of sentence, curator of the elderly, civil, ordinary procedure, misdemeanor, civil (guardianship / ban), measure of protection and providence request. The content analysis showed that demands the intervention of the public prosecutor has very peculiar characteristics in the city studied, because of the 77 demands, only 3 refer to services unavailable in the public health system. Therefore, despite being subject to demands from prosecutors $96.11 \%$ of requests were for services or supplies available in the city. The study concluded that the demands presented in 2010 , none was recorded in the health ombudsman. This demonstrates that there is no double door for citizens to access their rights. However, the ombudsman does not work in these cases, prior entry to the Public Prosecutor may indicate a lack of knowledge of its existence or function.
\end{abstract}

Keywords: Brazilian Public Health System; Prosecutor; Public Ombudsman; Right to Health.

\title{
Introdução
}

A Constituição Federal de 1988 dedicou o capítulo IV para descrever o Ministério Público, que é definido como "instituição permanente, essencial à função jurisdicional do Estado, incumbindo-lhe a defesa da ordem jurídica, do regime democrático e dos interesses sociais e individuais indisponíveis". (1) De acordo com Daher "hoje,

\footnotetext{
${ }^{1}$ BRASIL. Constituição da República Federativa do Brasil. Disponível em: <http://www.planalto.gov. br/ccivil_03/Constituicao.htm>. Acesso em: 20 set. 2011.
} 
o Ministério Público se afigura como autêntico advogado dos interesses sociais, dos interesses difusos e coletivos. É titular da ação que se fizer necessária para proteger o que é de todos". (2) Na visão dessa autora, os membros do Ministério Público desempenham prioritariamente a função de "advogados da sociedade" e, por essa razão, a figura do Ombudsman não foi recepcionada na Constituição Federal exatamente porque as atribuições que lhe são pertinentes já constavam como inerentes aos membros do Ministério Público. ${ }^{(3)}$ Porém, é preciso facilitar o acesso do cidadão às instituições de defesa de seus direitos, tanto que a Emenda Constitucional 45 propôs a criação das ouvidorias de justiça com o objetivo de "receber reclamações e denúncias de qualquer interessado contra membros ou órgãos do Poder Judiciário, ou contra seus serviços auxiliares, representando diretamente ao Conselho Nacional de Justiça". ${ }^{4)}$

Por outro lado, o desenvolvimento do campo do direito sanitário demonstra os anseios da sociedade por fazer valer suas garantias constitucionais e carece ainda de uma compreensão multidisciplinar que articule duas áreas extremamente complexas: saúde e direito.

Assim, esta pesquisa teve como principal objetivo estudar as demandas apresentadas à secretaria municipal de saúde pelo Ministério Público e identificar possibilidades de atuação da ouvidoria em um município de pequeno porte. Foi considerado o teor das demandas, no sentido de compreender as dificuldades de acesso encontradas pelos cidadãos e buscar a mediação entre as demandas e a gestão em saúde. Os objetivos específicos foram: analisar as demandas, oferecer subsídios para a gestão do Sistema Único de Saúde (SUS) municipal no planejamento das ações de saúde e verificar a existência de dupla porta de entrada para garantir o direito à saúde.

A relevância da pesquisa ficou demonstrada na articulação dos dois campos - saúde e direito -, considerando a intervenção do Ministério Público como oportunidade de qualificação do planejamento em saúde.

Para cumprir os objetivos propostos foi realizada pesquisa de natureza exploratória e qualitativa que utilizou como método o estudo de caso, cujas unidades de análise foram as demandas apresentadas à secretaria municipal de saúde de um município de pequeno porte, no período de janeiro a dezembro de 2010.

\footnotetext{
${ }^{2}$ DAHER, M.P. O Ministério Público. Jus Navegandi, Teresina, ano 5, n. 42, 1 jun. 2000. Disponível em: <http://jus.com.br/revista/texto/266>. Acesso em: 20 set. 2011.

${ }^{3}$ Id. Ibid.

${ }^{4}$ BRASIL. Emenda Constitucional n ${ }^{\circ} 45$, de 30 de dezembro de 2004. "Altera dispositivos dos arts. $5^{\circ}, 36,52,92,93,95,98,99,102,103,104,105,107,109,111,112,114,115,125,126,127,128$, 129, 134 e 168 da Constituição Federal, e acrescenta os arts. 103-A, 103B, 111-A e 130-A, e dá outras providências". Disponível em: <http://www.planalto.gov.br/ccivil_03/Constituicao/Emendas/ Emc/emc45.htm>. Acesso em: 29 mar. 2013.
} 


\section{As ouvidorias - canais de participação e cidadania}

As ouvidorias são consideradas um canal privilegiado para disseminação de informação sobre as políticas públicas de saúde e de manifestação dos usuários. Encontramos nos estudos de Pellegrini a referência de que "a informação e o conhecimento são bens públicos essenciais e que as iniquidades de acesso a esses bens são importantes determinantes das iniquidades em saúde". ${ }^{(5)}$ As ouvidorias contribuem para o processo democrático pela sua característica de ampliação da capacidade do poder instituído de interagir com a sociedade.

Autores como Vasquez et al. apontam que nos anos 1970 a participação comunitária é a tônica central das políticas públicas. Entendemos como consequência direta desse movimento no âmbito das políticas de saúde o surgimento de canais institucionais em que o cidadão possa manifestar sua opinião e contribuir democraticamente para a gestão pública. ${ }^{(6)}$ É dentro dessa lógica que foram criados os conselhos de saúde, após a Constituição Federal de 1988, que estabeleceu o SUS, posteriormente regulamentado pelas Leis $n^{\circ} 8.080 / 90^{(7)}$ e $n^{\circ}$ $8.142 / 90 .{ }^{(8)} O$ sistema de queixas e sugestões, ainda de acordo com Vasquez et al., também surge nesse contexto, objetivando facilitar o acesso do cidadão aos sistemas públicos. ${ }^{(9)}$

"Outro elemento básico para a participação da população no sistema de saúde é o acesso à informação, como instrumento fundamental para a democratização dos serviços." (10) Assim, as ouvidorias públicas de saúde incorporam esses dois elementos acolhendo as manifestações dos cidadãos e disponibilizando informações sobre a política pública de saúde no âmbito de sua atuação. Consideramos que sem informação todos os possíveis mecanismos de participação ficam comprometidos.

\footnotetext{
${ }^{5}$ PELLEGRINI FILHO, A. Pesquisa em saúde, política de saúde e eqüidade na América Latina. Ciência \& Saúde Coletiva, Rio de Janeiro, v. 9, n. 2, p. 339-350, 2004. Disponível em: <http:// www.scielo.br/scielo.php?pid=S1413-81232004000200011\&script=sci_arttext>. Acesso em: 20 set. 2011.

${ }^{6}$ VAZQUEZ, M.L. et al. Nível de informação da população e utilização dos mecanismos institucionais de participação social em saúde em dois municípios do Nordeste do Brasil. Ciência \& Saúde Coletiva, Rio de Janeiro, v. 10, p. 141-155, 2005.

${ }^{7}$ BRASIL. Lei $n^{\circ} 8.080$, de 19 de setembro de 1990. "Dispõe sobre as condições para a promoção, proteção e recuperação da saúde, a organização e o funcionamento dos serviços correspondentes e dá outras providências". Disponível em: <http://www.planalto.gov.br/ccivil_03/Leis/L8080.htm>. Acesso em: 29 mar. 2013.

${ }^{8}$ BRASIL. Lei $n^{\circ}$ 8.142, de 28 de dezembro de 1990. "Dispõe sobre a participação da comunidade na gestão do Sistema Único de Saúde e sobre as transferências intergovernamentais de recursos financeiros na área da saúde e dá outras providências". Disponível em: <http://www.planalto.gov. br/ccivil_03/LEIS/L8142.htm>. Acesso em: 29 mar. 2013.

9 VAZQUEZ, M.L. et al. op. cit.

${ }^{10}$ Id. Ibid.
} 


\section{Breve histórico das ouvidorias}

O primeiro projeto de instalação de ouvidorias no Brasil surge na iniciativa privada, que implantou a figura do ouvidor nos moldes do ombusdman sueco para defender os interesses do consumidor. Posteriormente, em 1986, a Prefeitura de Curitiba instituiu a primeira ouvidoria da administração pública, também com o objetivo de defender os interesses do cidadão. ${ }^{(11)}$

Segundo Vismona, durante o processo constituinte brasileiro de 1987/1988 buscou-se inscrever no texto constitucional a institucionalização do ombudsman, porém a tentativa não logrou êxito, pois naquela época não se tinha ainda a devida clareza de suas atribuições. ${ }^{(12)}$

Em 1989, foi inserido no jornal Folha de São Paulo o primeiro ombudsman da imprensa brasileira, ganhando visibilidade e divulgando a importância da atividade. A implantação do Código de Defesa do Consumidor, em 1990, estimulou as empresas a implantarem ouvidorias como canal eficaz para a solução de conflitos entre consumidores e elas próprias. ${ }^{(13)}$

O Estado do Paraná, em 1991, criou o cargo de Ouvidor Geral através de decreto governamental, concedendo-Ihe, conforme aponta Oliveira, o status e prerrogativas de secretário de Estado. Desenvolveu-se, a partir de então, um sistema de ouvidorias em todos os órgãos da administração direta e indireta, surgindo as ouvidorias especializadas, todas referenciadas à Ouvidoria Geral. Esse modelo, por se mostrar eficaz, foi posteriormente implantado em outros Estados, a exemplo do Ceará. ${ }^{(14)}$

Já em 1995 foi possível acontecer o I Encontro Nacional de Ouvidores/Ombudsman, em João Pessoa (PB). Das discussões realizadas na ocasião surgiu a ideia de congregar os ocupantes da incipiente função de ouvidores em uma associação nacional. Foi então criada a Associação Brasileira de Ouvidores/ Ombudsman $(\mathrm{ABO})$ reunindo entre seus membros tanto os ocupantes de cargos públicos como privados. Desde então, essa instituição tem se preocupado em estimular a criação de novas ouvidorias, com foco na defesa irrestrita dos direitos do cidadão. ${ }^{(15)}$ Encontraremos mais tarde a obrigatoriedade estabelecida através de emenda constitucional para que todos os tribunais de Justiça e o Ministério Público instituíssem suas ouvidorias. ${ }^{(16)}$

\footnotetext{
11 VISMONA, E.L. A ouvidoria no Brasil e seus princípios. Revista IMESP, São Paulo, n. 1, dez. 1998. Disponível em: <http://www.imesc.sp.gov.br.htm>. Acesso em: 13 mar. 2011.

12 Id. Ibid.

${ }^{13}$ OLIVEIRA, J.E. et al. A ouvidoria brasileira: dez anos da Associação Brasileira de Ouvidores. São Paulo: Imprensa Oficial do Estado de São Paulo, 2005.

${ }^{14}$ Id. Ibid.

${ }^{15}$ Id. Ibid.

${ }^{16}$ BRASIL. Emenda Constitucional n 45, de 30 de dezembro de 2004. op.cit.
} 
Oliveira destaca dois importantes marcos legais para as ouvidorias no Brasil: a chamada "Lei de Defesa do Usuário de serviços públicos do Estado de São Paulo", de 1999, ${ }^{(17)}$ que estabeleceu a obrigatoriedade de instalação de ouvidorias em todas as Secretarias do Estado, e a emenda constitucional da reforma do Judiciário. ${ }^{(18)}$

\section{Ouvidorias públicas de saúde}

Apesar de a implantação da primeira ouvidoria pública no Brasil datar de 1986, recentemente é que observamos o crescimento desses órgãos, em especial no setor da saúde.

A partir de 2006, com o Pacto pela Saúde, acordo firmado entre os três entes federados, gestores do SUS, estabeleceu-se como parâmetro a descentralização da política nacional de ouvidorias do SUS. ${ }^{(19)}$ Como em outras áreas, o Ministério da Saúde iniciou uma política indutiva com repasse de equipamentos e tecnologia para estimular a implantação de ouvidorias da saúde no âmbito de estados e municípios, especialmente, no caso destes últimos, aqueles com mais de 100 mil habitantes.

Segundo Souza et al., a ouvidoria em saúde pode ser definida como uma ferramenta de mediação entre usuários, gestores e trabalhadores do setor, na busca pelo aperfeiçoamento dos serviços e ações oferecidos. ${ }^{(20)} \mathrm{O}$ funcionamento de uma ouvidoria em saúde acontece por meio da escuta, sistematização, análise e encaminhamento das demandas recebidas, que vão desde pedidos de informações e esclarecimento de dúvidas a reclamações, elogios e denúncias. Dessa forma, uma manifestação única e individual pode culminar, se bem encaminhada, na solução de problemas coletivos e no aprimoramento dos serviços de saúde para toda a população.

No âmbito do SUS, foi criado o Sistema Nacional de Ouvidorias como estratégia para consolidar o modelo de gestão participativa, cuja base é participação comunitária. ${ }^{(21)}$ Da mesma forma, os Estados e municípios são estimulados a implantar em seu território as ouvidorias, que devem preferencialmente ser

\footnotetext{
17 SÃO PAULO. Lei no 10.294, de 20 de abril de 1999. "Dispõe sobre proteção e defesa do usuário do serviço público do Estado de São Paulo e dá outras providências". Disponível em: <http://www. cidadao.sp.gov.br/protecao_lei.php>. Acesso em: 29 mar. 2013.

${ }^{18}$ BRASIL. Emenda Constitucional ${ }^{\circ}$ 45, de 30 de dezembro de 2004. op.cit.

19 BRASIL. Portaria $n^{\circ}$ 399, de 22 de fevereiro de 2006. "Divulga o Pacto pela Saúde 2006 consolidação do SUS e aprova diretrizes operacionais do referido pacto". Diário Oficial da União, Brasília, 22 fev. 2006.

${ }^{20}$ SOUZA, L.A. et al. Apostila do curso de capacitação profissional em ouvidoria do SUS: programa de educação à distância: módulo I - contextual: introdução ao SUS, Brasília: Universidade de Brasília, 2007.

${ }^{21}$ MINISTÉRIO DA SAÚDE. Secretaria de Gestão Estratégica e Participativa. Departamento de Ouvidoria Geral do SUS. Falando de Ouvidoria: experiências e reflexões. Brasília, 2010.
} 
regulamentadas através de decreto ou portaria. Portanto, as ouvidorias em saúde podem ser criadas em todas as esferas de governo, atuando em parceria com os conselhos de saúde e demais segmentos de controle social existentes. Por ter essa função principal de mediar relações, a ouvidoria não pode exercer funções fora do seu campo de atuação nem intervir na resolução dos problemas; afinal, seu papel é servir de ligação entre as partes, promovendo a comunicação para que sejam encontradas respostas às demandas apresentadas.

Para exercerem seu papel com plenitude, as instituições responsáveis por criar as ouvidorias em saúde precisam garantir que usuários, servidores e gestores da área tenham fácil acesso a esse canal de comunicação. Dessa forma, as ouvidorias oferecem aos cidadãos a oportunidade de participar e contribuir diretamente no desenvolvimento de ações no campo da saúde. Além disso, as ouvidorias acabam funcionando como um "termômetro" da administração pública ao fazerem um ordenamento da leitura das demandas originárias daqueles que fazem uso do sistema único de saúde. ${ }^{(22)}$ Através dos registros feitos pelas ouvidorias, o governo local pode conhecer mais detalhadamente as carências específicas de cada setor do sistema de saúde ou região geográfica, informações que podem auxiliar os gestores na tomada de decisões. Assim, o trabalho realizado pelas ouvidorias deve ser muito mais eficaz no auxílio à resolução de problemas, em alguns casos, do que pesquisas de opinião ou de satisfação.

\section{Direito à saúde no Brasil}

A Constituição Federal de 1988 estabelece em seu Art. 196 que saúde é direito de todos e dever do Estado. Como cenário para a emergência desse direito recente no Brasil, encontramos a Declaração Universal dos Direitos Humanos proclamada pela Assembleia Geral das Nações Unidas em 10 de dezembro de 1948. ${ }^{(23)}$

A política pública prioritária para a efetivação do direito à saúde é o SUS regulamentado pela Lei $n^{\circ} 8.080 / 90$. A Lei $n^{\circ} 8.142 / 90$, editada logo em seguida, regulamenta a participação da comunidade na formulação e acompanhamento da política pública de saúde.

Do ponto de vista jurídico, o direito à saúde é classificado no escopo dos direitos sociais ou direitos humanos de segunda geração. Assim, o Art. $6^{\circ}$ da Constituição Federal estabelece que "são direitos sociais a educação, a saúde, o trabalho, a moradia, o lazer, a segurança, a previdência social, a proteção à maternidade e à infância, a assistência aos desamparados, na forma desta Constituição". Como prerrogativa, os direitos sociais exigem que o Estado defina políticas públicas

\footnotetext{
22 OLIVEIRA, J. E. et al. op. cit.

${ }^{23}$ DALLARI, S.G. et al. Advocacia em saúde no Brasil contemporâneo. Revista de Saúde Pública, São Paulo, v. 30, n. 6, p. 592-601, 1996.
} 
para a sua efetivação e, no caso da saúde, que estabeleça ações concretas e efetivas para sua promoção, proteção e recuperação.

Por outro lado, o direito à saúde é considerado como um direito público subjetivo, o que faculta ao indivíduo a possibilidade de exigir do Estado, através de ação judicial, o acesso aos meios e procedimentos para manter sua condição de saúde. ${ }^{(24)}$

A Constituição Federal estabelece, ainda no Art. 197,(25) o caráter de relevância pública das ações e serviços de saúde. De acordo com Aith,

o reconhecimento da saúde como um direito humano fundamental deu origem a uma profusão de normas e decisões jurídicas que têm o escopo de garantir esse importante direito, dando vida e conteúdo a uma parte específica da ciência jurídica, que chamamos de direito sanitário. ${ }^{(26)}$

Consideramos, pois, que operadores do direito e gestores do SUS dispõem de instrumentos jurídicos importantes para lidar com o Direito à saúde, especialmente quando o Estado não oferece garantias para sua efetivação.

\section{Cenário do estudo}

O estudo foi realizado em município de Minas Gerais, com uma população estimada em 34.391 habitantes, conforme dados do IBGE. O sistema de saúde local é organizado tendo como porta de entrada a Estratégia de Saúde da Família, atualmente com $100 \%$ de cobertura populacional. A rede de saúde é bem estruturada e potencialmente resolutiva, conforme demonstrado no diagnóstico que compõe o Plano Municipal de Saúde.

A primeira Conferência Municipal de Saúde foi realizada em 1991 e neste mesmo ano foi instalado o Conselho Municipal de Saúde. A ouvidoria de saúde foi implantada em 2009.

\section{Material e método}

Foi realizada pesquisa de natureza exploratória e qualitativa utilizando como método o estudo de caso, cujas unidades de análise foram as demandas apresentadas à secretaria municipal de saúde, pelo Ministério Público, no período de janeiro a dezembro de 2010. A fonte para coleta de dados foram os ofícios encaminhados pelo Ministério Público à secretaria municipal de saúde com as solicitações de ações ou serviços que deveriam ser atendidos pelo gestor do SUS.

\footnotetext{
${ }^{24}$ AITH, F. Curso de direito sanitário: a proteção do direito à saúde no Brasil. São Paulo: Quartier Latin, 2007.

${ }^{25}$ BRASIL. Constituição da República Federativa do Brasil. Disponível em: <http://www.planalto.gov. br/ccivil_03/Constituicao.htm>. Acesso em: 20 set. 2011.

${ }^{26}$ Id. Ibid.
} 
A pesquisa documental consistiu, portanto, na análise de 77 ofícios recebidos em 2010. A definição das variáreis para fins deste estudo contemplou todas as informações disponíveis nos ofícios, que são: assunto, natureza e teor, conforme redação que segue um padrão adotado pelo escrivão judicial.

A análise do teor das manifestações foi realizada com base em categorias estabelecidas para classificar as demandas do Ministério Público de acordo com os níveis de complexidade de atenção à saúde adotados pelo SUS: atenção primária, atenção especializada e alta complexidade.(27),(28)

\section{Resultados e discussão}

No ano de 2010, a secretaria municipal de saúde recebeu 77 demandas oriundas do Ministério Público, que foram encaminhadas através de ofício ao gabinete do secretário municipal de saúde, diretamente ou por meio da Procuradoria do Município, quando o destinatário era o prefeito municipal, mas o teor referia-se à política municipal de saúde. Em 75 casos (97,40\%), oficiou-se diretamente o gestor do SUS municipal. As demandas foram analisadas e respondidas pelo secretário municipal adjunto de saúde, com consulta às áreas assistenciais, quando identificada necessidade de esclarecimentos técnicos.

A Tabela 1 apresenta as demandas direcionadas ao Sistema Municipal de Saúde, categorizadas por assunto, conforme registrado pelo escrivão judicial.

Tabela 1. Demandas judiciais por assunto, 2010.

\begin{tabular}{lc}
\hline Assunto & $\mathrm{n}$ \\
\hline Comunicação & 1 \\
Inflamação & 4 \\
Recomendação & 1 \\
Requisição de atendimento & 1 \\
Requisição de informações & 6 \\
Solicitação de providências & 64 \\
\hline Total & 77 \\
\hline
\end{tabular}

Fonte: SMS Brumadinho

Fonte: Secretaria Municipal de Saúde

Conforme podemos verificar, os assuntos tratados nas demandas foram classificados como: comunicação (1), intimação (4), recomendação (1),

\footnotetext{
${ }^{27}$ CONASS. Conselho Nacional de Secretários de Saúde: atenção primária e promoção da saúde. Brasília: CONASS, 2007 (Coleção Progestores - Para entender a gestão do SUS, Livro 8).

${ }^{28}$ Id. Conselho Nacional de Secretários de Saúde: assistência de média e alta complexidade no SUS. Brasília: CONASS, 2007 (Coleção Progestores - Para entender a gestão do SUS, Livro 9).
} 
requisição de atendimento (1), requisição de informações (6) e solicitação de providências (64). Assim, encontramos uma diversidade que não caracteriza somente demandas por medicamentos ou procedimentos, como é usual na literatura sobre o tema.

A Tabela 2 apresenta as demandas categorizadas pela natureza, conforme descrição dos ofícios encaminhados.

Tabela 2. Demandas por natureza, 2010.

\begin{tabular}{lc}
\hline Natureza & $\mathrm{n}$ \\
\hline JIJ - Pedido de Providência/Cível & 16 \\
JIJ - Medidas de proteção/ECA - Maus tratos & 24 \\
Cível - Curatela/Interdição & 4 \\
Contravenção penal & 6 \\
Procedimento ordinário & 1 \\
Cível - Regulamentação de visitas & 1 \\
Curadoria do idoso & 1 \\
Execução de pena & 1 \\
Não informado & 23 \\
\hline Total & 77 \\
\hline
\end{tabular}

Fonte: SMS Brumadinho

Fonte: Secretaria Municipal de Saúde

1. Verificamos que, de um total de 77 demandas apresentadas no ano de 2010, as naturezas descritas são:

2. Execução de pena (1) - trata-se de encaminhamento de cidadão para prestação de serviços comunitários em unidade de saúde.

3. Curadoria do idoso (1) - encaminha questões referentes à violação de direitos das pessoas com 60 anos ou mais.

4. Cível - regulamentação de visita (1) - nesse caso o juiz solicita o acompanhamento de profissionais de saúde durante visita do pai aos filhos menores.

5. Procedimento ordinário (1) - refere-se a demandas para as quais a lei não previu forma especial, como é o caso dos idosos, crianças e adolescentes.

6. Contravenção penal (6) - a inclusão em tratamento foi indicada como pena para reparar a contravenção em se tratando de primeira ocorrência.

7. Medidas de proteção (24) - oriundas da justiça da infância e juventude, contemplam decisões fundamentadas no Estatuto da Criança e do 
Adolescente, ${ }^{(29)}$ com o objetivo de proteger o menor exposto a situações de risco em consequência do comportamento de seus genitores e/ou responsáveis. Alguns exemplos são: requisição de tratamento, inclusão em programa de orientação e tratamento a alcoólatras e toxicômanos, colocação em família substitutiva, dentre outras.

8. Pedido de providência cível (16) - contempla solicitações para inclusão em tratamento nas unidades de saúde de crianças, adolescentes e adultos.

9. Outras 23 não apresentam no corpo do ofício a natureza da demanda.

A análise dos dados descritos anteriormente demonstra a especificidade da atuação do Ministério Público junto ao SUS municipal. Das 77 demandas, 36 $(46,75 \%)$ contemplam solicitações de inclusão em tratamentos que estão disponíveis na rede assistencial de saúde local. O texto constitucional incumbe o Ministério Público de defender os interesses sociais e individuais indisponíveis. No entanto, constatamos que no município em questão, apesar de o plano municipal indicar a disponibilidade dos tratamentos solicitados, os usuários recorreram ao Ministério Público para solucionar suas necessidades de saúde. Portanto, no caso estudado, a indisponibilidade do direito à saúde indica que, apesar da oferta de serviços públicos, os cidadãos enfrentam dificuldades de acesso. Por outro lado, os achados na literatura demonstram que, em geral, as intervenções do Ministério Público são consequência da dificuldade de acesso a ações e/ou serviços de saúde pela inexistência de procedimentos e/ou serviços na rede assistencial de saúde.

Verificamos que, das 77 demandas analisadas, 44 (57,14\%) referem-se a solicitações de tratamento para crianças e/ou adolescentes. Através de conversa com membro do conselho tutelar, em evento de capacitação para conselheiros municipais, obtivemos a informação de que o conselheiro tutelar nem sempre é atendido pelas unidades de saúde quando solicita inclusão em tratamento. Temos, pois, por hipótese que o acesso ao Ministério Público indica uma desarticulação entre a rede assistencial de saúde e os dispositivos da rede de proteção social do município; neste caso, o conselho tutelar.

Através dos dados apresentados no Gráfico 3, poderemos verificar as demandas por procedimento/tratamento classificadas por nível de complexidade (atenção especializada e atenção primária) e por tipo de solicitação (transporte sanitário, assistência farmacêutica e ajuda de custo através do tratamento fora do domicílio - TFD). De acordo com o Guia do SUS o TFD é um atendimento prestado pela Secretaria de Saúde quando esgotados todos os meios de tratamento no município, por exemplo: quimioterapia, radioterapia, hemodiálise. ${ }^{(30)}$

\footnotetext{
${ }^{29}$ BRASIL. Lei n ${ }^{\circ} 8.069$, de 13 de julho de 1990. "Dispõe sobre o Estatuto da Criança e do Adolescente e dá outras providências". Disponível em: <http://www.planalto.gov.br/ccivil_03/Leis/L8069.htm>. Acesso em: 29 mar. 2013.

${ }^{30}$ BRASIL. Lei $n^{\circ} 8.069$, de 13 de julho de 1990. op.cit.
} 
De acordo com os dados apresentados na Tabela 3 podemos verificar que:

Tabela 3. Demandas por nível de complexidade e tipo de solicitação, 2010.

\begin{tabular}{lc}
\hline Nível de complexidade e tipo de solicitação & $\mathrm{n}$ \\
\hline Atenção especializada & 51 \\
Atenção primária & 22 \\
Transporte sanitário & 2 \\
Assistência farmacêutica & 1 \\
TFD & 1 \\
\hline Total & 77 \\
\hline
\end{tabular}

Fonte: Secretaria Municipal de Saúde

1. $51(66,23 \%)$ demandas representam solicitações de procedimentos de atenção especializada - solicitações de inclusão em tratamento para dependência de álcool e outras drogas. Desse montante, 49 (96,07\%) solicitações indicavam tratamento ambulatorial, que é disponibilizado pelo SUS municipal, e apenas 2 (3,92\%) demandas se referiam a internação em clínica especializada;

2. $22(28,57 \%)$ referem-se a procedimentos prestados na Atenção Primária;

3. duas $(2,60 \%)$ solicitações de transporte sanitário;

4. uma $(1,30 \%)$ solicitação de medicamento através da assistência farmacêutica; e

5. uma $(1,30 \%)$ referente a tratamento fora do domicílio através do fornecimento de ajuda de custo e transporte para tratamento de quimioterapia.

Autores como Sant'Ana apontam que "pesquisas conduzidas em diferentes regiões do país revelam que o número de ações movidas contra o Estado pleiteando medicamentos vem crescendo acentuadamente nos últimos anos". (31) Analisando as ações impetradas contra a Secretaria Municipal de Saúde de São Paulo, Vieira e Zucchi demonstraram as distorções e os efeitos sobre a política de medicamentos. ${ }^{(32)}$ Este estudo, no entanto, revela que no período analisado somente uma demanda solicitava fornecimento de medicação. Podemos com isso inferir que o acesso a medicamentos no município estudado é um direito que tem sido respeitado. A assistência farmacêutica municipal oferece atendimento através da Farmácia Especial, onde os cidadãos são orientados sobre o

31 SANT'ANA, J.M.B. Essencialidade e assistência farmacêutica: um estudo exploratório das demandas judiciais individuais para acesso a medicamentos no Estado do Rio de Janeiro. 2009. Dissertação (Mestrado) - Escola Nacional de Saúde Pública Sérgio Arouca, Rio de Janeiro, 2009.

32 VIEIRA, F.S.; ZUCCHI, P. Distorções causadas pelas ações judiciais à política de medicamentos no Brasil. Revista de Saúde Pública, São Paulo, v. 41, n. 2, p. 214-22, 2007. 
protocolo a seguir para ter acesso a medicamentos que não são padronizados. De acordo com informações do setor de serviço social, no ano de 2010 existiam aproximadamente 194 pacientes cadastrados e os medicamentos solicitados foram comprados pela secretaria municipal de saúde mediante prescrição médica e laudo social.

Para contribuir com o planejamento e avaliação dos serviços ofertados à população, apresentaremos a seguir os tipos de solicitações feitas nos dois setores mais demandados, que foram: atenção especializada em saúde mental e atenção primária, correspondendo a $51(66,23 \%)$ e $22(28,57 \%)$ solicitações, respectivamente.

A Tabela 4 apresenta as demandas referentes à atenção especializada em saúde mental. Os dados demonstram que 34 (66,66\%) procedimentos referem-se a atenção integral a usuários de álcool e outras drogas, sendo 32 (62,74\%) para tratamento ambulatorial que já é disponibilizado pela secretaria municipal de saúde. Além disso, é importante destacar que, conforme informação disponível no Plano Municipal de Saúde, trata-se de município de pequeno porte com facilidade de acesso geográfico e capacidade instalada para atendimento às demandas de tratamento em saúde mental.

Tabela 4. Demandas do Ministério Público - atenção especializada em saúde mental, 2010.

\begin{tabular}{lc}
\hline Tipo de Tratamento & $\mathrm{n}$ \\
\hline Álcool e outras drogas - tratamento ambulatorial & 32 \\
Álcool e outras drogas - internação em clínica especializada & 2 \\
Psicoterapia e consulta psiquiátrica & 3 \\
Exame psiquiátrico pericial & 6 \\
Psicoterapia & 5 \\
Atendimento no CAPS & 2 \\
Consulta psiquiátrica & 1 \\
\hline Total & 51 \\
\hline
\end{tabular}

Fonte: Secretaria municipal de saúde, 2010

Através dos dados apresentados na Tabela 5, verifica-se que as 22 demandas referentes a atenção primária solicitam ações e serviços também disponíveis no município. Conforme demonstra o plano municipal de saúde (2010 - 2013), o sistema de saúde local é organizado tendo como porta de entrada da atenção primária a Estratégia de Saúde da Família, com cobertura de $100 \%$ da população. Sendo assim, não era de esperar que as ações desse nível de atenção fossem solicitadas através da atuação do Ministério Público.

É importante considerar que a intervenção do Ministério Público no campo da saúde, no município cenário de nosso estudo, apresenta características bastante distintas do que encontramos na literatura e não produziu impactos 
Tabela 5. Demandas do Ministério Público - atenção primária, 2010.

\begin{tabular}{lc}
\hline Tipo de tratamento & $\mathrm{N}$ \\
\hline Visita por ACS & 4 \\
Acompanhamento pela ESF & 5 \\
Emissão de relatórios de acompanhamento & 6 \\
Solicita cópia de prontuário médico & 1 \\
Visita domiciliar & 4 \\
Encaminhamento ao CRAS & 1 \\
Consulta ginecológica & 1 \\
\hline Total & 22
\end{tabular}

financeiros adicionais na gestão do SUS, uma vez que os serviços solicitados já estão implantados na rede assistencial de saúde. No entanto, foi importante constatar que os cidadãos não estão conseguindo acessar diretamente a rede de serviços e, por isso, foi necessária a intervenção do Ministério Público. Conforme relatado anteriormente, uma conselheira tutelar alega que ocorre descumprimento, pelos profissionais de saúde, do Estatuto da Criança e do Adolescente, especialmente em seu Art.11:

É assegurado atendimento integral à saúde da criança e do adolescente, por intermédio do Sistema Único de Saúde, garantido o acesso universal e igualitário às ações e serviços para promoção, proteção e recuperação da saúde.

E ainda podemos afirmar, baseado no depoimento da conselheira, que há um desconhecimento da função do conselho tutelar, que tem a prerrogativa estabelecida em lei de requisitar serviços públicos nas áreas de saúde. ${ }^{(33)}$

Nesse estudo procurou-se verificar a existência de dupla porta de entrada para a reivindicação do direito à saúde, comparando as demandas apresentadas pela Ouvidoria e pelo Ministério Público. Constatamos através do Relatório Anual de Gestão que, de 362 manifestações registradas na Ouvidoria em 2010, nenhuma contempla o mesmo tipo de atendimento solicitado através do Ministério Público. Portanto, o estudo não identificou dupla porta de entrada no acesso ao sistema público de saúde. Por outro lado, é possível constatar que a Ouvidoria ainda não é um dispositivo suficientemente conhecido e utilizado pelos cidadãos, pois poderia ser utilizada como recurso anterior ao Ministério Público. Conforme estabelecido pela política nacional de ouvidorias do SUS, elas surgem "como mais um serviço para o fortalecimento da participação social e da qualificação

\footnotetext{
${ }^{33}$ BRASIL. Lei $n^{\circ} 8.069$ de 13 de julho de 1990. op.cit.
} 
da gestão no SUS". ${ }^{(34)}$ Como parte da estrutura organizativa da secretaria de saúde a Ouvidoria está mais próxima da rede de atenção e pode responder com agilidade às demandas dos cidadãos. Além disso, quando a atuação da Ouvidoria antecede a ação do Ministério Público, denota-se que foram esgotados todos os recursos do poder Executivo à disposição do cidadão para a efetivação do direito à saúde, e, então, justifica-se o apelo ao Ministério Público.

\section{Considerações Finais}

O objetivo deste trabalho foi estudar as demandas do Ministério Público para identificar possibilidade de atuação da ouvidoria de saúde como ferramenta de gestão e planejamento em saúde.

Conforme demonstrado, muitas demandas são originadas pelo fato de o cidadão não acessar diretamente o sistema de saúde, já que os serviços estão disponíveis.

O fato de que as demandas não foram previamente registradas pelos cidadãos na ouvidoria pode indicar um desconhecimento por parte do Ministério Público e, também pelos conselheiros tutelares, da existência ou da função da ouvidoria de saúde. Consideramos, portanto, oportuno realizar um trabalho de divulgação externa da Ouvidoria, especialmente voltado para o Ministério Público e conselhos vinculados à rede de proteção social existente no município. Essa ação poderá facilitar e desburocratizar o acesso dos cidadãos e dos órgãos de defesa dos direitos, como é o caso do Conselho Tutelar, aos serviços e ações de saúde.

Este trabalho demonstrou que a dificuldade de acesso à maioria dos serviços e/ou procedimentos não ocorreu pela inexistência deles na rede de atenção à saúde. Estudos futuros poderão averiguar por que os cidadãos estão tendo dificuldade para acessar esses serviços.

Consideramos, também, que o desenvolvimento de um trabalho integrado entre as diversas políticas públicas municipais, especialmente a saúde, educação e assistência social, poderá contribuir para a efetivação do direito à saúde. Nesse sentido, lembramos o conceito de saúde proposto pela Organização Mundial da Saúde (OMS): "saúde não é apenas ausência de doença, mas a situação de um perfeito bem-estar físico, mental e social”. (35) Portanto, a efetivação desse direito humano fundamental não está restrita à atuação da secretaria municipal de saúde.

\footnotetext{
${ }^{34}$ MINISTÉRIO DA SAÚDE. Secretaria de Gestão Estratégica e Participativa. Departamento de Ouvidoria Geral do SUS. Guia de orientações básicas para implantação de ouvidorias do SUS. Brasília: 2009.

${ }^{35}$ SEGRE, M.; FERRAZ, F.C. O conceito de saúde. Revista de Saúde Pública, São Paulo, v. 31, n. 5, p. 538-542, 1997.
} 
Esta pesquisa contribuiu com a gestão do SUS na medida em que caracterizou as demandas originadas pelo Ministério Público e constatou que, no caso desse município de pequeno porte, essa intervenção no campo da saúde não implica em sobrecarga financeira para o sistema, mas pode indicar uma desarticulação das políticas públicas. Os resultados obtidos indicam que há um desconhecimento dos fluxos e protocolos que regulam o funcionamento do SUS municipal. Em contrapartida, identificou-se por meio do depoimento de uma conselheira que há por parte dos profissionais de saúde falta de clareza e desrespeito ao caráter legal que regula a atuação do conselho tutelar.

A facilidade de acesso aos arquivos da secretaria municipal de saúde e ao trabalho da ouvidoria, que encontramos neste estudo, nem sempre é realidade em municípios maiores. No entanto, essa aproximação é necessária para que, de fato, as ouvidorias cumpram seu papel como espaço de cidadania e ferramenta de gestão.

\section{Referências}

AITH, F. Curso de direito sanitário: a proteção do direito à saúde no Brasil. São Paulo: Quartier Latin, 2007.

CONASS. Conselho Nacional de Secretários de Saúde: assistência de média e alta complexidade no SUS. Brasília: CONASS, 2007 (Coleção Progestores Para entender a gestão do SUS, Livro 9).

Conselho Nacional de Secretários de Saúde: atenção primária e promoção da saúde. Brasília: CONASS, 2007 (Coleção Progestores - Para entender a gestão do SUS, Livro 8).

DAHER, M.P. O Ministério Público. Jus Navegandi, Teresina, ano 5, n. 42, 1 jun. 2000. Disponível em: <http://jus.com.br/revista/texto/266>. Acesso em: 20 set. 2011.

DALLARI, S.G. et al. Advocacia em saúde no Brasil contemporâneo. Revista de Saúde Pública, São Paulo, v. 30, n. 6, p. 592-601, 1996.

MINISTÉRIO DA SAÚDE. Secretaria de Gestão Estratégica e Participativa. Departamento de Ouvidoria Geral do SUS. Falando de ouvidoria: experiências e reflexões. Brasília, 2010.

Secretaria de Gestão Estratégica e Participativa. Departamento de Ouvidoria Geral do SUS. Guia de orientações básicas para implantação de ouvidorias do SUS. Brasília, 2009.

OLIVEIRA, J.E. et al. A ouvidoria brasileira: dez anos da Associação Brasileira de Ouvidores. São Paulo: Imprensa Oficial do Estado de São Paulo, 2005. 
PELLEGRINI FILHO, A. Pesquisa em saúde, política de saúde e eqüidade na América Latina. Ciência \& Saúde Coletiva, Rio de Janeiro, v. 9, n. 2, p. 339-350, 2004. Disponível em: <http://www.scielo.br/scielo.php?pid=S1413$81232004000200011 \&$ script=sci_arttext>. Acesso em: 20 set. 2011.

SANT'ANA, J.M.B. Essencialidade e assistência farmacêutica: um estudo exploratório das demandas judiciais individuais para acesso a medicamentos no Estado do Rio de Janeiro. 2009. Dissertação (Mestrado) - Escola Nacional de Saúde Pública Sérgio Arouca, Rio de Janeiro, 2009.

SEGRE, M.; FERRAZ, F.C. O conceito de saúde. Revista de Saúde Pública, São Paulo, v. 31, n. 5, p. 538-542, 1997.

SOUZA, L.A. et al. Apostila do curso de capacitação profissional em ouvidoria do SUS: programa de educação à distância: módulo I - contextual: introdução ao SUS, Brasília: Ed. da Universidade de Brasília, 2007.

VAZQUEZ, M.L. et al. Nível de informação da população e utilização dos mecanismos institucionais de participação social em saúde em dois municípios do Nordeste do Brasil. Ciência \& Saúde Coletiva, Rio de Janeiro, v. 10, p. 141155, 2005.

VIEIRA, F.S.; ZUCCHI, P. Distorções causadas pelas ações judiciais à política de medicamentos no Brasil. Revista de Saúde Pública, São Paulo, v. 41, n. 2, p. 214-22, 2007.

VISMONA, E.L. A ouvidoria no Brasil e seus princípios. Revista IMESP, São Paulo, n. 1, dez. 1998. Disponível em: <http://www.imesc.sp.gov.br.htm>. Acesso em: 13 mar. 2011. 